\title{
DESIGN AND DEVELOPMENT OF U-SLOT OPEN STUBS PARTIAL GROUND PLANE RECTANGULAR MICROSTRIP ANTENNA FOR WIRELESS COMMUNICATION APPLICATIONS
}

\author{
Syeda Rafath Ara', S. N. Mulgi ${ }^{2}$ \\ ${ }^{1}$ Dept. of P. G. Studies and Research in Applied Electronics, Gulbarga University, Kalaburagi-585 106, Karnataka, \\ India \\ ${ }^{2}$ Dept. of P. G. Studies and Research in Applied Electronics, Gulbarga University, Kalaburagi-585 106, Karnataka, \\ India
}

\begin{abstract}
This paper presents the design and development of U-slot, open stubs microstripline feed partial ground plane rectangular microstrip antenna for broadband wireless communication applications. By inserting U-slot of dimension $0.625 \mathrm{~cm}$ the antenna gives a bandwidth of $92.6 \%$ with a virtual size reduction of $38.88 \%$ with gain of $4.19 \mathrm{~dB}$. However this $92.6 \%$ of bandwidth can be enhanced to $138 \%$ again by placing two stubs simultaneously on left and right side of microstripline without effecting the gain and virtual size reduction. The antennas are designed on low cost modify epoxy substrate material of dielectric constant $\varepsilon_{r}=4.2$ and $h=0.16 \mathrm{~cm}$ at $3 \mathrm{GHz}$. The antennas are use full for WiMAX, LAN, Bluetooth and IEEE 802.11 a application.
\end{abstract}

Keywords - U-slot, Open stubs, Partial ground plane

\section{INTRODUCTION}

The recent wireless communication technology requires an antenna with a compact radiating structure, enhanced bandwidth and capable of adequate gain. To fulfill this many techniques are reported in the literature [1-5]. Some are like introducing slots on radiating patch and ground plane, use of tuning stubs, parasitic patches, single line feed arrangements [6-11] etc. The radiating patch antenna with a single line feed and a partial ground plane is becoming more popular in these applications. Recently the design of broadband antennas has become a challenging task. In view of this a design and development of U-slot implanted on the radiating patch and open stubs placed simultaneously on left and right side of the single microstripline feed on the same patch with partial ground plane for satisfying the bandwidth requirements for wideband communication is presented. The novel geometries of the proposed antennas are very simple and compact can be easily fabricated and mounted with any other device, cost effective and gives large gain compared to the conventional antenna defined for the same resonant frequency.

\section{ANTENNA GEOMETRY AND DESIGN}

The proposed antennas are designed on modified glass epoxy substrate material with a dielectric constant 4.2 and height of substrate is $0.16 \mathrm{~cm}$ at $3 \mathrm{GHz}$. The rectangular shape is selected as patch geometry due to its simplicity in design and fabrication. A single microstripline feeding technique and partial ground plane is used for exciting the antennas. A U-slot of length $\mathrm{L}_{\mathrm{u}}=1 \mathrm{~cm}$ and width $\mathrm{W}_{\mathrm{u}}=0.25 \mathrm{~cm}$ is placed on the patch. The geometry of U-slot rectangular microstrip antenna (USRMSA) with parameters is as shown in Fig. 1. In Fig. $1 \mathrm{~L}$ and $\mathrm{W}$ are the length and width of the rectangular patch and $\mathrm{L}_{\mathrm{f}}$ and $\mathrm{W}_{\mathrm{f}}$ are the length and width of the microstripline feed, $\mathrm{L}_{\mathrm{s}}$ and $\mathrm{W}_{\mathrm{s}}$ are the length and width of the substrate and $\mathrm{L}_{\mathrm{g}}$ is the height of the partial ground plane.

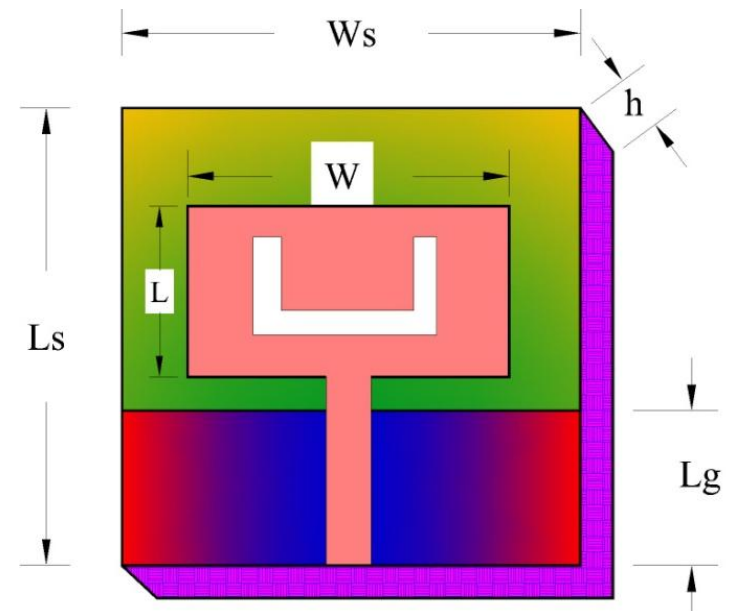

Fig. 1 Geometry of USRMSA

For better performance working on USRMSA after number of iterations two open stubs S1 and S2 with identical dimensions of length $\mathrm{L}_{1}=0.4 \mathrm{~cm}$ and width $\mathrm{W}_{1}=0.55 \mathrm{~cm}$ are placed on left and right side of the microstripline feed. The geometry of U-slot with open stub rectangular microstrip antenna (USWSRMSA) is as shown in Fig. 2 (a) and (b). Figure 2(a) shows the top view and Fig. 2(b) shows the side view geometry of USWSRMSA. The ground plane of this antenna is same as that of Fig. 1. 


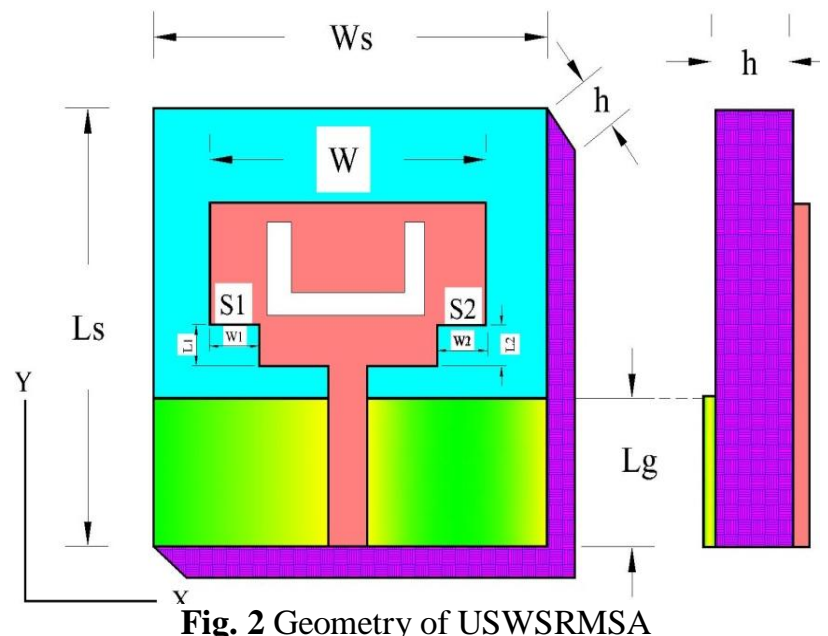

\section{RESULTS AND DISCUSSIONS}

The simulations of proposed antennas are performed using HFSS simulating software. The return loss characteristic of USRMSA is as shown in Fig. 3. It is seen that, the antenna operates for single band of bandwidth $\mathrm{BW} 92.6 \%$ ranging from $1.38-3.76 \mathrm{GHz}$ with two resonant frequencies at 1.76 and the second at $3.07 \mathrm{GHz}$ with virtual size reduction of $38.88 \%$ compared to the designed frequency of $3 \mathrm{GHz}$. The operating range of this antenna covers PCS (1.85 - 1.99 GHz), WCDMA (1.92 - 2.17), LTE 2300 (2300 - 2400 MHz), WLAN (2.4 - 2.48 GHZ), GPS ( $1-3 \mathrm{GHz})$ bands for wireless communication applications.

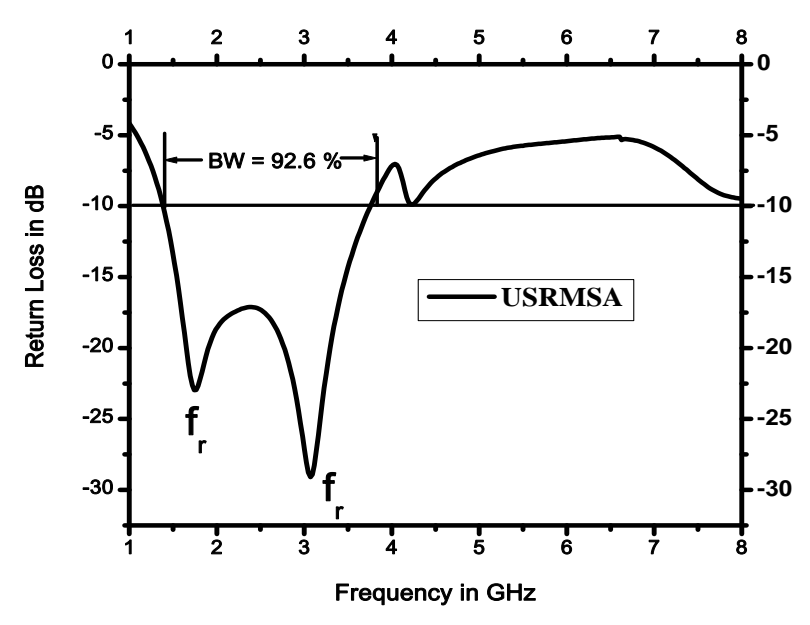

Fig. 3 Variation of return loss versus frequency curve of USRMSA

Fig. 4 shows the return loss characteristics of USWSRMSA. When two open stubs of same dimensions placed on left and right side of the microstripline feed it is seen that the antenna resonates from $1.45-8.02 \mathrm{GHz}$ and gives a bandwidth of $138 \%$ which is $45 \%$ more than the bandwidth of USRMSA with four resonant modes at 1.78, 3.83, 4.62 and $.178 \mathrm{GHz}$ with a virtual size reduction of $38.19 \%$. The gain of the antenna measured with operating band. The peak gain of this antenna is found to be $4.19 \mathrm{~dB}$ which is quite large compared to the conventional rectangular microstrip antenna designed for the same resonant frequency of $3 \mathrm{GHz}$ which is nearly equal to $1 \mathrm{~dB}$ [12]. The operating band of USWSRMSA covers almost all present microwave frequencies used for various wireless communication applications.

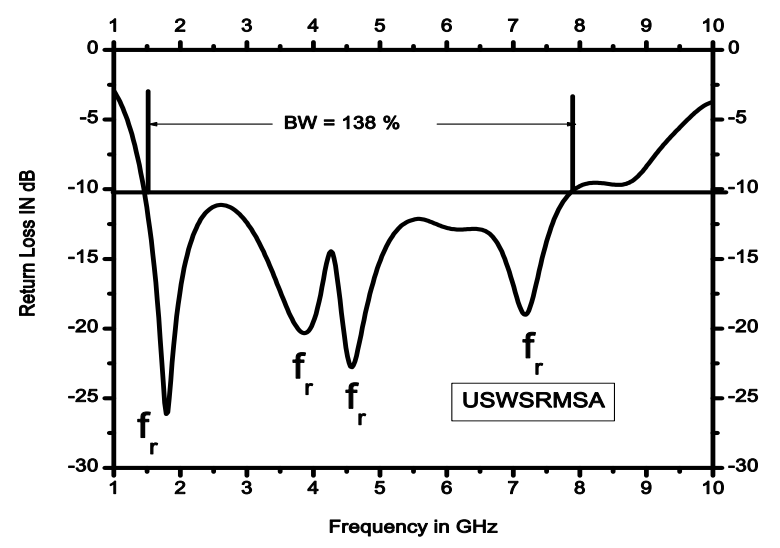

Fig. 4 Variation of return loss versus frequency of USWSRMSA

The surface current distributions on patch and ground plane of USWSRMSA measured at resonance frequencies are shown in Fig. 5 (a) to (d) where the currents are mainly concentrated around the U-slot, open stubs and on corners of the ground plane, makes the antenna resonates for wide frequency range.

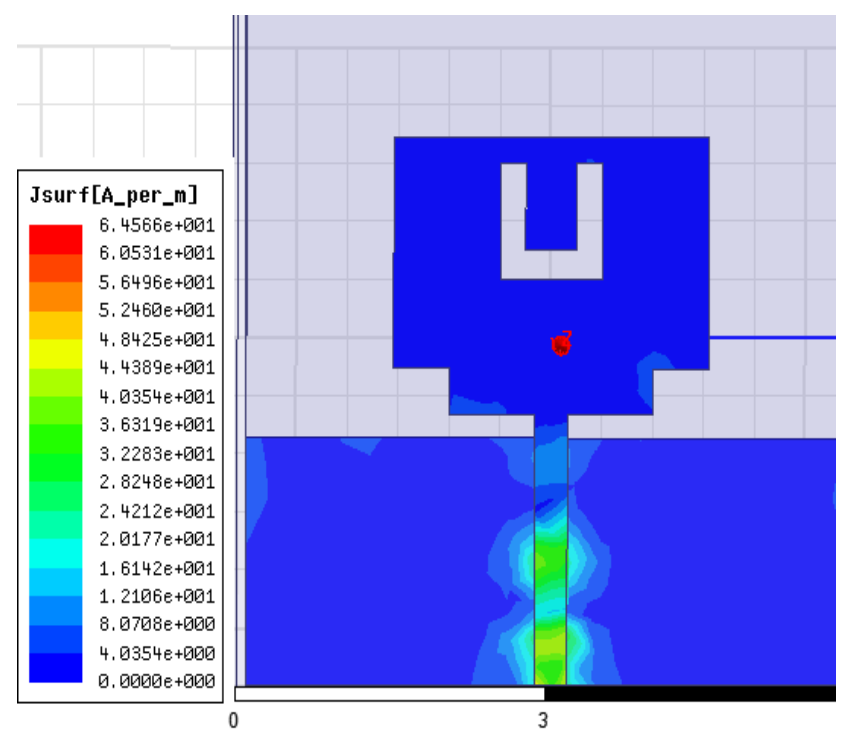

(a) at $1.78 \mathrm{GHz}$ 


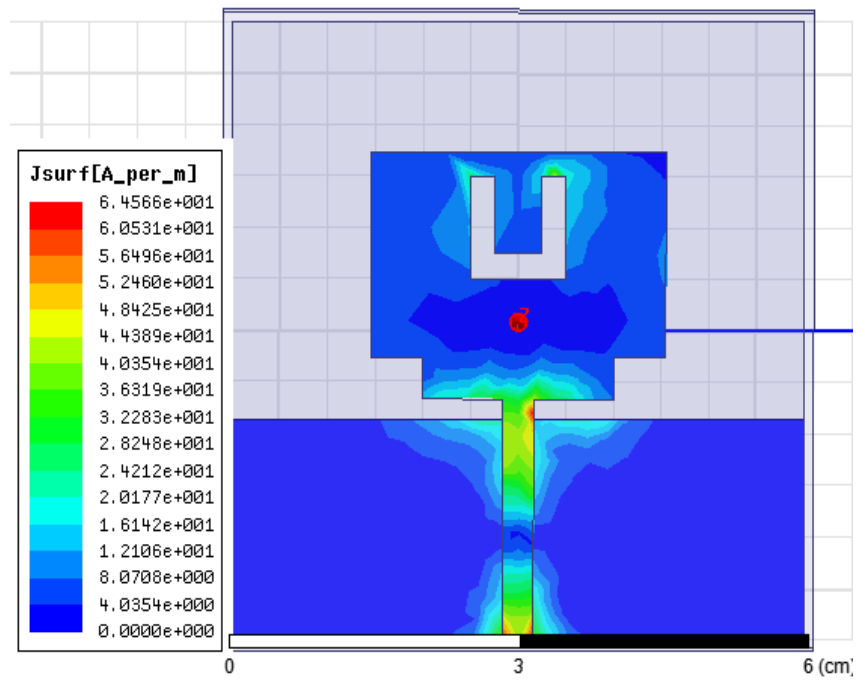

(b) at $3.83 \mathrm{GHz}$

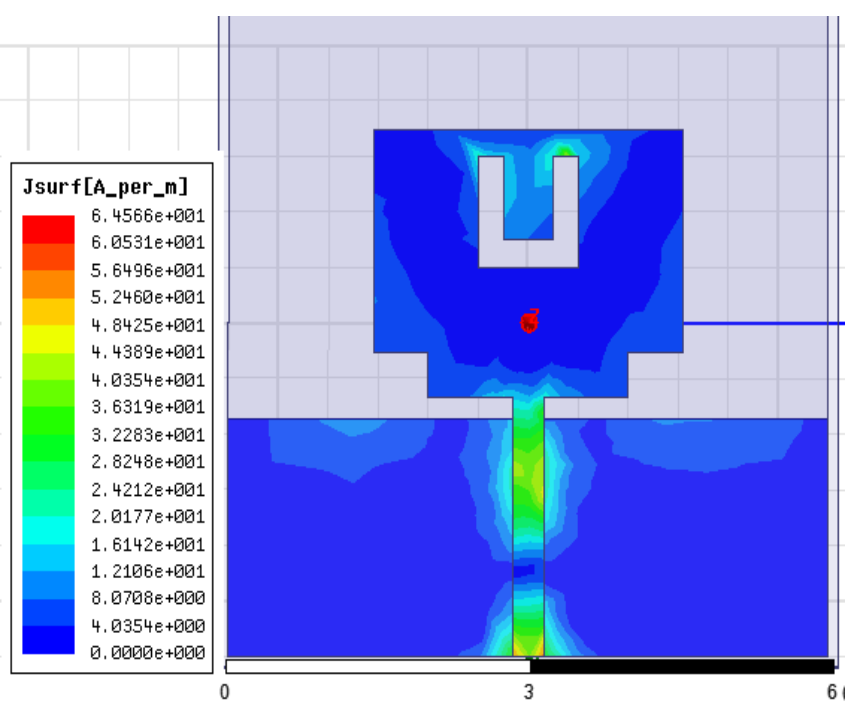

(c) at $4.62 \mathrm{GHz}$

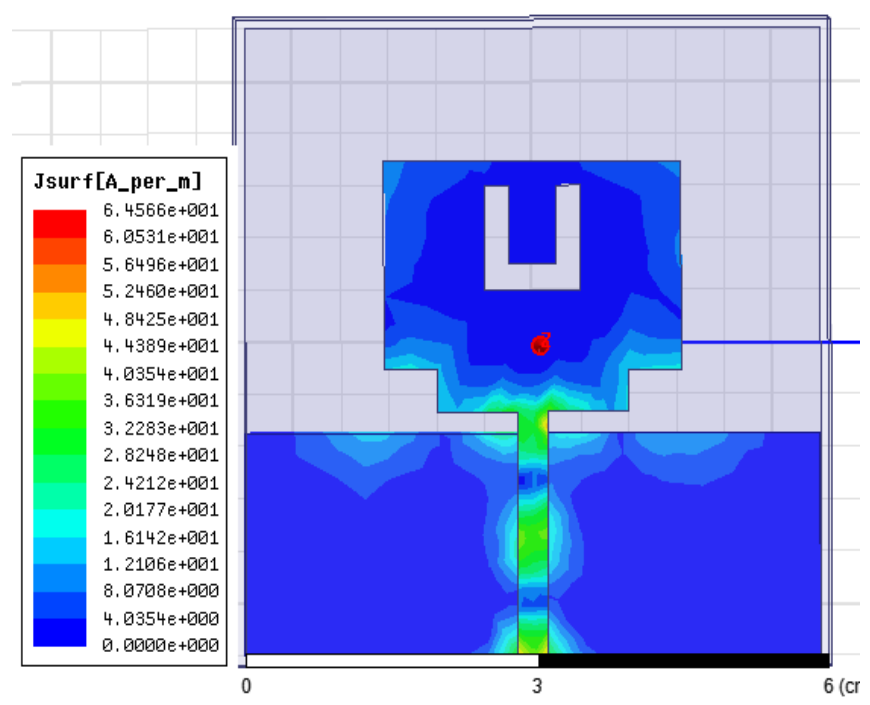

(d) at $7.18 \mathrm{GHz}$

Fig. 5 Surface current distribution of USWSRMSA measured at resonant frequencies $1.78,3.83,4.62$ and 7.18 $\mathrm{GHz}$
The radiation patterns of USWSRMSA measured at resonant frequencies of $1.78,3.83,4.62$ and $7.18 \mathrm{GHz}$ are shown in Fig. 6 (a) to (d) respectively. It is clear that, the antenna shows nearly omnidirectional radiation pattern.

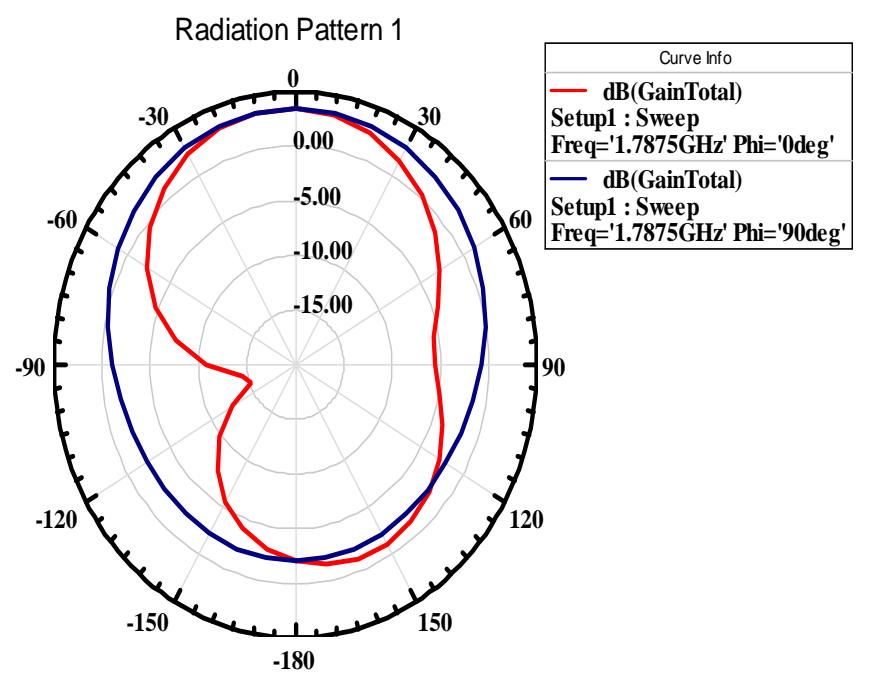

(a) at $1.78 \mathrm{GHz}$

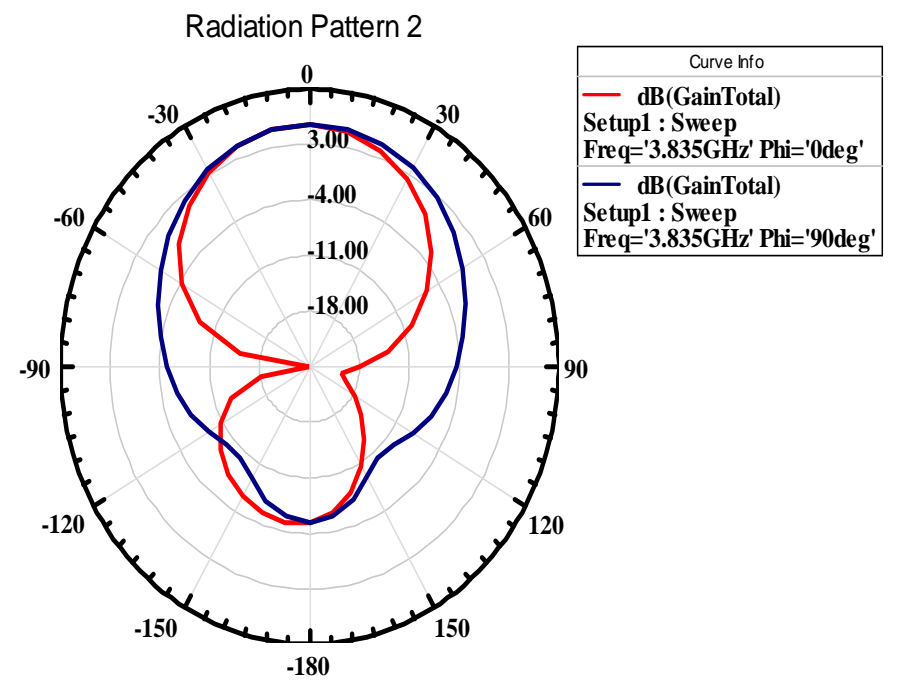

(b) at $3.83 \mathrm{GHz}$

Radiation Pattern 3

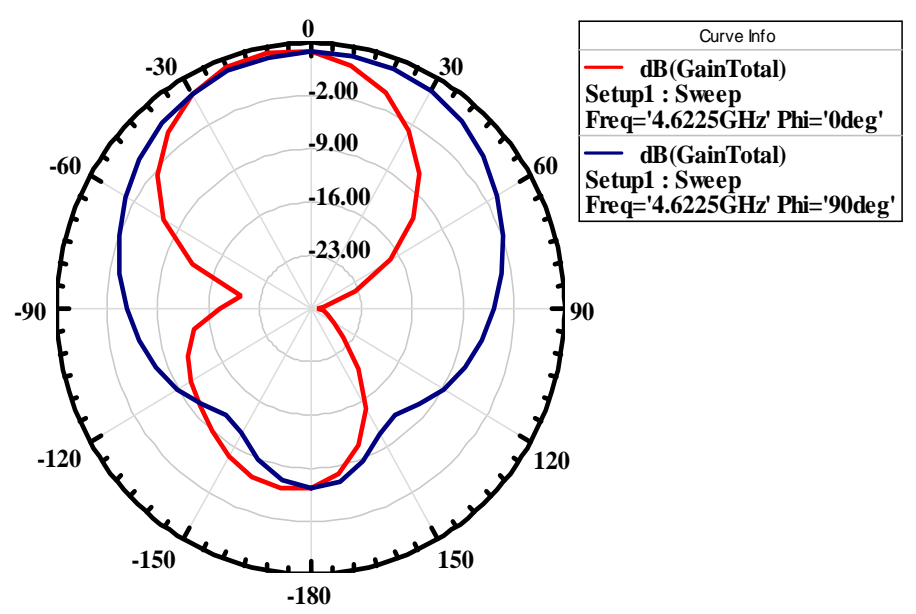

(c) at $4.62 \mathrm{GHz}$ 


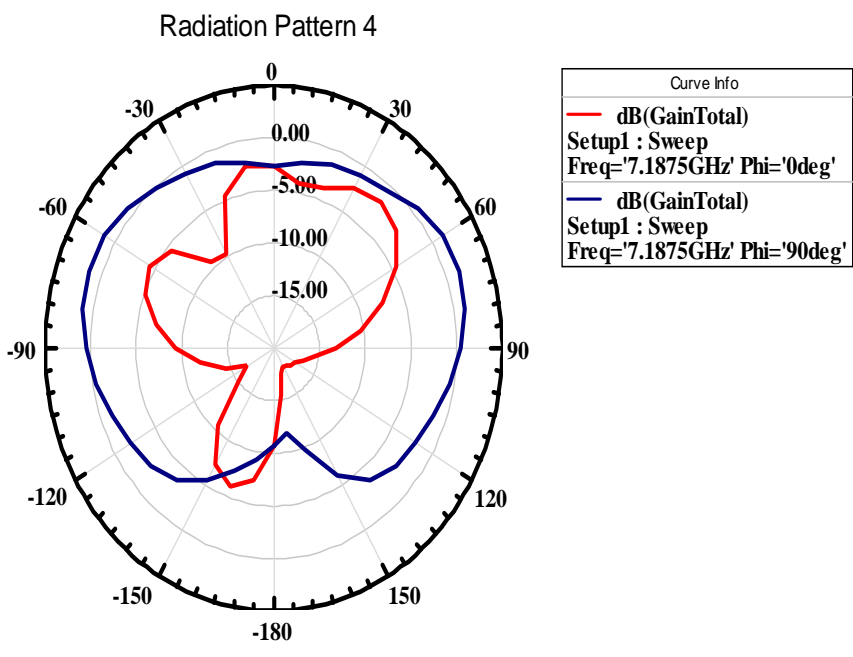

(d) at $7.18 \mathrm{GHz}$

Fig.6 Typical radiation pattern of USWSRMSA

\section{CONCLUSION}

In this work it is found that, a simple U-slot single microstripline feed and partial ground plane rectangular microstrip antenna gives bandwidth of $92.6 \%$ with a virtual size reduction of $38.88 \%$ and the gain is $4.19 \mathrm{~dB}$. However, the $138 \%$ of bandwidth is obtained which is enhanced from $92.6 \%$ by placing two open stubs of same dimensions on left and right side of the microstripline of USRMSA without effecting much the gain and virtual size reduction. The proposed antennas are simple in its geometry, cost effective and quite useful for many microwave communication applications.

\section{REFERENCES}

[1] R. Garg and P. Bhartia, "Microstrip antenna handbook", Artech house, Boston, (2001).

[2] J. R. James and P. S. Hall, "Handbook of Microstrip Antennas", Peter Peregronic Ltd., London,

[3] Qing-Xin Chu and Liang-Hua Ye, "Design of compact dual-wideband antenna with assembled monopoles," IEEE Trans. Antennas Propag., vol. 58, no. 12, pp. 4063-4066, Apr. 2004.

[4] Ahmad R. Razali and Marek E. Bialkowski, "Dualband slim inverted-f antenna with enhanced operational bandwidth," Microwave And Optical Technology Letters, vol. 54, No. 3, pp. 684-689, March 2012.

[5] A.R. Razali and M.E. Bialkowski, "Coplanar inverted-F antenna with open-end ground slots for multi-band operation," IEEE Antennas Wireless Propagation Letters, vol. 8, pp. 1029-1032, 2009.

[6] Vedaprabhu, "A Double U-slot Patch Antenna with Dual Wideband Characteristics", Microwave Laboratory, ECE Dept., Indian Institute of Science, Bangalore, India.

[7] W. S. Chen and K. Y. Ku, "Broadband design of non-symmetric ground $\lambda / 4$ open slot antenna with small size", Microwave Journal, vol. 50, (2007), pp. 110-121.
[8] Ali and L. Neyestanak, "W-shaped enhanced bandwidth patch antenna for wireless communication", Wireless Pers. Communication, vol. 43, (2007), pp. 1257-1265.

[9] F. Yang, X.-X. Zhang, X. Ye and Y. Rahmat-Samii, "Wide-band E-shaped patch antennas for wireless communications", IEEE Transactions on Antennas and Propagation, vol. 49, (2001) July 7, pp. 1091100.

[10] K Ashwini Arya., M.V. Kartikeyan, A Patnaik , "Defected Ground Structure in the perspective of Microstrip Antennas," A Review in Frequenz 5-6, 64, pp.79-84, 2010.

[11] E Antonino-Daviu, M Cabedo-Fabres , M FerrandoBataller and A Nogueira Valero ,"A Wideband double-fed planar monopole antennas", IEEE Electronics Letters, 39(23),pp.1635-1636, 2003.

[12] N. M. Sameena, R. B. Konda, DR. S. N. Mulgi., “A Novel Slot for Enhancing Impedence Bandwidth and Gain of Rectangular Microstrip Antenna ," PIERS online, pp.11-19, 2009. 